\title{
CONVERSION OF METHYL ESTER FATTY ACID FROM RICE BRAN OIL INTO FUEL FRACTION VIA HYDROCRACKING REACTION OVER ZEOLITE CATALYST SUPPORTED OF Ni, Co AND Mo METALS
}

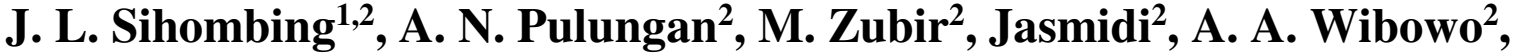 \\ S. Gea ${ }^{3, *}$, B. Wirjosentono ${ }^{3}$ and Y. A. Hutapea ${ }^{3}$ \\ ${ }^{1}$ Postgraduate School, Department of Chemistry, Faculty of Mathematic and Natural Science, \\ University of Sumatera Utara, 20155, Indonesia \\ ${ }^{2}$ Department of Chemistry, Universitas Negeri Medan, Jl. Willem Iskandar Pasar V, \\ Medan Estate, Medan 20221, Indonesia \\ ${ }^{3}$ Department of Chemistry, University of Sumatera Utara, Jl. Bioteknologi No. 1, \\ Medan 20155,Indonesia \\ *E-mail: s.gea@usu.ac.id
}

\begin{abstract}
The purpose of this research was to produce bio-gasoline fraction from methyl ester fatty of rice bran oil through catalytic hydrocracking systems. The following method was; 1) Preparation and impregnation of $\mathrm{Ni}$, Co and $\mathrm{Mo}$ metals inactivated commercial natural zeolite (CNZ-A) to be NiO/CNZ-A, NiOMoO/CNZ-A and NiOCoOMoO/CNZ-A, 2) Production of methyl ester fatty acid (MEFA) from rice bran oil using esterification and trans-esterification process, and 3) Catalytic hydrocracking MEFA at a temperature of $350^{\circ} \mathrm{C}, 400^{\circ} \mathrm{C}$ and $450^{\circ} \mathrm{C}$ respectively. Furthermore, the characterization of catalysts using X-ray Diffraction (XRD) resulted in no significant changes in crystal systems and catalysts were indicated as a mordenite. Then, the analyzing of nitrogen adsorption through the Brunauer-Emmett-Teller (BET) method depicts the reducing in the surface area of catalysts, however, the mean pore and pore volume of catalysts experienced an increasing trend. Moreover, the highest liquid product was $90.24 \%$ of $\mathrm{NiO}-\mathrm{CoO}-\mathrm{MoO} / \mathrm{CNZ}-\mathrm{A}$ catalyst $\left(400^{\circ} \mathrm{C}\right)$, with selectivity for gasoline and diesel fractions was $28.34 \%$ and $71.65 \%$, respectively. In essence, the three metals (Ni,Co and Mo) gave the highest percentage of biogasoline products among the three catalysts.
\end{abstract}

Keywords:Catalyst, Bio-diesel, Bio-gasoline, Hydrocracking, ActivatedCommercial Natural Zeolite (CNZ-A)

(C) RASĀYAN. All rights reserved

\section{INTRODUCTION}

A renewable energy source which possesses a great potential to be developed in Indonesia is biomass. According to Zeng et al. (2006), vegetable oil and animal fat are sources of renewable biomass, other than the fuel produced with bio-degradable properties and contains almost no sulfur and categorized as environmental friendly. ${ }^{1,2}$

The research related to the conversion of vegetable oil into fuel fractions through a catalytic cracking process has been developed. The catalytic cracking process aims to break the long carbon chains into molecules with a shorter carbon chain by catalyst support. ${ }^{3,4}$ Gaya (2003) reported the cracking of the vegetable oil (vegetable oils), animal oils and fatty acids and methyl esters of fatty acids at high temperatures in generated the hydrocarbon light fraction (light hydrocarbons). ${ }^{5}$ The light fraction of hydrocarbons is the bio-gasoline fuel which has more percentage than the biodiesel. Several types of research have been significantly investigated towards the catalytic cracking palm oil to produce fuel fraction. ${ }^{6-11}$

Rasayan J. Chem., 12(1), 205-213(2019)

http://dx.doi.org/10.31788/RJC.2019.1215036

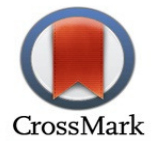


Vegetable oils were developed in Indonesia from palm oil and jatropha oil, which the current research has been achieved on the utilization of palm oil and castor oil to substitute diesel fuel (diesel fuel). However, these materials have a limitation as palm oil is the edible oil with high value. Edible oils as a raw material for biodiesel affects as $60 \%-70 \%$ to the price of biodiesel. On the other hand, Jatropha oil production is still low production level due to lack of land to plant jatropha trees. ${ }^{12,13}$ Therefore, there should be an alternative raw material that will produce alternative bio-gasoline fuels at affordable prices and easy to apply to the public.

One of the alternative raw materials that can be developed is rice bran oil obtained from rice bran extraction with organic solvents. Rice bran is a byproduct of milled rice grain. Rice bran contains high free fatty acid (FFA) with around $16 \%-32 \%$ of its weight mass. The high content of free fatty acids (FFA) in extracts of rice bran oil causing it to be easily converted into methyl ester fatty acid (MEFA) through the esterification and trans-esterification process.Then, the catalytic cracking process will produce a light hydrocarbon fraction or called as bio-gasoline. ${ }^{14}$

Generally, the catalyst used is a heterogeneous catalyst which has a surface area and a high acid content[15]. The catalyst was prepared by dispersing one or more active metals into the carrier material as a catalyst [16]. Some of the materials that can be used as a carrier of metal components are silica, alumina, zeolite and carbon. One type of zeolite used as a carrier is mordenite. ${ }^{16}$ Trisunaryanti et al. (1996) discovered that the Indonesian natural zeolite contains an amorphous and crystalline silica mordenite with $70 \%$ content. ${ }^{17}$ In this study, an active natural zeolite was impregnated with metals, namely Nickel, Cobalt, and Molybdenum as catalysts in MEFA rice bran catalytic hydrocracking process into liquid fuel in the fixed-bed reactor system.

\section{Treatment of Commercial Natural Zeolite}

\section{EXPERIMENTAL}

Commercial Natural Zeolite was soaked in distilled water for 24 hours at room temperature. Then, the zeolite was filtered, and the precipitation was dried at a temperature of $100^{\circ} \mathrm{C}$, to be referred to commercial natural zeolite (CNZ). Commercial natural zeolite (CNZ) which was cleaned in the early treatment was then dealuminated with $\mathrm{HCl} 3 \mathrm{M}$ and then refluxed at $90{ }^{\circ} \mathrm{C}$ for 30 minutes. The solution resulted from reflux process was filtered, and then the precipitation was washed with distilled water to remove the $\mathrm{HCl}$ (indicated with no more formation of precipitation with the addition of $\mathrm{AgNO}_{3}$ in the filtrate). The precipitation was filtered and dried at $120{ }^{\circ} \mathrm{C}$ for 3 hours, then calcined at $500^{\circ} \mathrm{C}$ with flowing nitrogen gas. The result was referred to an activated commercial natural zeolite (CNZ-A).

\section{NiO/CNZ-A Catalyst Preparation}

All reagents were purchased from Merck. As many as $4.93 \mathrm{~g}$ of $\mathrm{Ni}\left(\mathrm{NO}_{3}\right)_{2} \cdot 6 \mathrm{H}_{2} \mathrm{O}$ was dissolved in distilled water in a round bottom flask. Then, an amount of $100 \mathrm{~g}$ of activated commercial natural zeolite (CNZ-A) was added and refluxed with stirring process 5 hours at $80^{\circ} \mathrm{C}$. After that, it was dried and referred as NiCNZ-A catalyst. The solid Ni-CNZ-A was then calcined at $500^{\circ} \mathrm{C}$ with flowing nitrogen gas $( \pm 5 \mathrm{~mL} / \mathrm{sec})$ for 2 hours, then oxidized with oxygen gas flow $( \pm 5 \mathrm{~mL} / \mathrm{sec})$ at $500{ }^{\circ} \mathrm{C}$ for 2 hours. This result was referred to $\mathrm{NiO} / \mathrm{CNZ}-\mathrm{A}$ catalyst.

\section{NiO-MoO/CNZ-A Catalyst Preparation}

As many as $0.92 \mathrm{~g}$ of ammonium heptamolybdate tetrahydrate, $\left(\mathrm{NH}_{4}\right) 6 \mathrm{Mo}_{7} \mathrm{O}_{24} .4 \mathrm{H}_{2} \mathrm{O}$ was dissolved in aquabidest in a round-bottom flask, and $100 \mathrm{~g}$ of CNZ-A was added and refluxed by stirring process for 5 hours at $80{ }^{\circ} \mathrm{C}$. Then, it was dried and referred as Mo-ZAS catalyst. Then, a $2.47 \mathrm{~g}$ of nickel nitrate, Ni $\left(\mathrm{NO}_{3}\right)_{2} .6 \mathrm{H}_{2} \mathrm{O}$ was dissolved in aquabidest and added to Mo-CNZ-A.It was then refluxed by stirring process with for 5 hours at $80^{\circ} \mathrm{C}$ and then dried. It was referred to Ni-Mo-CNZ-A catalyst. An amount of $\mathrm{Ni}-\mathrm{Mo}-\mathrm{CNZ}-\mathrm{A}$ solid was calcined at $500^{\circ} \mathrm{C}$ with nitrogen gas flow $( \pm 5 \mathrm{~mL} / \mathrm{sec})$ for 2 hours, then oxidized by oxygen gas flow $\left( \pm 5 \mathrm{~mL} / \mathrm{sec}\right.$ ) at $500{ }^{\circ} \mathrm{C}$ for 2 hours. It was finally referred to NiO-MoO/CNZ-A catalyst.

\section{NiO-CoO-MoO/CNZ-A Catalyst Preparation}

An amount of $0.607 \mathrm{~g}$ of ammonium heptamolybdate tetrahydrate, $\left(\mathrm{NH}_{4}\right)_{6} \mathrm{Mo}_{7} \mathrm{O}_{24} .4 \mathrm{H}_{2} \mathrm{O}$ was dissolved in aquabidest on a round-bottom flask. Then, add an activated commercial natural zeolite (CNZ-A) was 
added and refluxed by stirring process for 5 hours at $80^{\circ} \mathrm{C}$. The resulted material was dried and referred to Mo-CNZ-A. Then, $1.670 \mathrm{~g}$ of cobalt nitrate, $\mathrm{Co}\left(\mathrm{NO}_{3}\right)_{2} \cdot 6 \mathrm{H}_{2} \mathrm{O}$ was dissolved in aquabidest and added to Mo-CNZ-A. It was then refluxed and stirred for 5 hours at $80^{\circ} \mathrm{C}$. Then, it was dried and obtaining the CoMo-CNZ-A. A total of $1.627 \mathrm{~g}$ of nickel nitrate, $\mathrm{Ni}\left(\mathrm{NO}_{3}\right)_{2} \cdot 6 \mathrm{H}_{2} \mathrm{O}$ was dissolved in aquabidest and then added to Co-Mo-CNZ-A. It was refluxed with the stirring process for 5 hours at a temperature of $80^{\circ} \mathrm{C}$. The resulted material was then dried and referred as NiCoMo-CNZ-A catalyst. The NiCoMo-CNZ-A solid was then calcined at $500^{\circ} \mathrm{C}$ with nitrogen gas flow $( \pm 5 \mathrm{~mL} / \mathrm{sec}$ ) for 2 hours, then oxidized by oxygen gas flow $\left( \pm 5 \mathrm{~mL} / \mathrm{sec}\right.$ ) at $500{ }^{\circ} \mathrm{C}$ for 2 hours. It was finally referred to $\mathrm{NiO}-\mathrm{CoO}-\mathrm{MoO} / \mathrm{CNZ}-\mathrm{A}$ catalyst.

\section{Catalyst Characterization}

Several characterizations of catalysts were conducted, namely; The acidity of the catalyst by gravimetric method with ammonia as a base of the absorption, XRD analysis by X-Ray Diffractometer - Shimadzu XRD-6000 at Physics Laboratory of Universitas Negeri Medan, Indonesia and determination of the surface area and the mean pore by BET method using NOVA Gas Sorption Analyzer NOVA1200eQuantachrome at Universitas Islam Negeri Yogyakarta, Indonesia.

\section{MEFA Rice Bran Preparation}

Around $50 \mathrm{~g}$ of rice bran oil was heated at $110^{\circ} \mathrm{C}$ for 30 minutes. Before the trans-esterification reaction, the esterification reaction of rice bran oil was prepared as a pre-treatment which containing a high free fatty acid. Comparison of the molar ratio of methanol: oil was $6: 1$ with $\mathrm{H}_{2} \mathrm{SO}_{4}$ catalyst $(1 \% \mathrm{v} / \mathrm{v}$ of the total volume of methanol + rice bran oil). $\mathrm{H}_{2} \mathrm{SO}_{4}$ and methanol solution was poured into a three-neck flask in which have contained rice bran oil. The reaction time was recorded from the mixing process, heated at $30^{\circ} \mathrm{C}$ temperature and kept the stirring speed $(100 \mathrm{rpm})$ constantly. After the trans-esterification reaction was completed, it was followed by adding $\mathrm{NaOH} 1 \% \mathrm{w} / \mathrm{w}$ as a catalyst and a neutralizer. The esterification reaction was performed at $60{ }^{\circ} \mathrm{C}$ for 1 hour and stirring speed was kept constant at $100 \mathrm{rpm}$. After the reaction was completed (1-hour reaction time), an amount of 3-5 drops of $0.6 \mathrm{~N} \mathrm{HCl}$ was then added to neutralize the catalyst until the reaction stopped. Then, the sample was added with $2.5 \mathrm{~mL}$ glycerin to obtain the methyl ester top layer, and the bottom layer containing glycerin was released and added with excess methanol, catalyst, soap formed and a small portion of methyl esters or glycerides were converted partially. The bottom layer of the drain layer and the methyl ester layer were washed and evaporated at $74{ }^{\circ} \mathrm{C}$ to remove the remaining methanol. Methyl ester layer was washed with distilled water several times to remove the residual catalyst. Furthermore, the methyl ester was dried with anhydrous $\mathrm{Na}_{2} \mathrm{SO}_{4}$. The samples were analyzed with GC HEWLETT PACARD 5890series at Pharmacy Faculty of University of Sumatera Utara, Indonesia.

\section{Hydrocracking Process}

MEFA hydrocracking process of rice bran oil was performed by the flow of hydrogen gas $(20 \mathrm{~mL} / \mathrm{min})$ in a fixed-bed reactor system with a ratio of feed/catalyst of $0.5(\mathrm{w} / \mathrm{w})$. The catalyst activity test was carried out at various temperatures of $350^{\circ} \mathrm{C}, 400^{\circ} \mathrm{C}$ and $450^{\circ} \mathrm{C}$ respectively and variations of the catalyst as $\mathrm{NiO} / \mathrm{CNZ}-\mathrm{A}, \mathrm{NiOMoO} / \mathrm{CNZ}-\mathrm{A}$ and NiO-CoO-MoO/CNZ-A to determine the optimum conditions of MEFA hydrocracking process of rice bran oil. The liquid product was determined with GC and then was calculated. ${ }^{18}$

\section{Catalyst Characterization}

\section{RESULTS AND DISCUSSION}

Preparation and activation treatment of commercial natural zeolite mineral aims to eliminate impurities within pores and reduce the amount of $\mathrm{Al}$ in the skeleton (dealumination) to produce a site with a high acid strength. The Lewis acid site shows at $1442-1450 \mathrm{~cm}^{-1}$ while the Bronsted acid site appears at 1540$1550 \mathrm{~cm}^{-1}{ }^{19}$ Figure-1 (IR analysis) shows that the acidification process causes dealumination. This process is causing the release of alumina from the zeolite tetrahedral framework structures.$^{20}$ It indicates the reduction of $\mathrm{Al}$ atoms in the framework to $\mathrm{Al}$ outer frame (non-framework). As qualitatively, the number fraction of the $\mathrm{Al}$ atoms contained in the tetrahedral structure of zeolite is directly proportional to the wavenumber range of asymmetric primary, so if there is a reduction of $\mathrm{Al}$ atomic on the structural 
RASĀYAN J. Chem.

Vol. 12 | No. 1 |205 - 213| January - March | 2019

frame zeolite, it will induce a shift wavenumber vibrational stretch of asymmetric cluster of $\mathrm{TO}_{4}(\mathrm{~T}=\mathrm{Si}$ and $\mathrm{Al}$ ) towards the higher frequency. ${ }^{20}$ The aluminium oxide vibration can be seen at $1000-500 \mathrm{~cm}^{-1} .{ }^{21}$ The commercial natural zeolite (CNZ) before acidification treatment with $\mathrm{HCl}$ has a range of asymmetric vibrational wavenumber at $1056.99 \mathrm{~cm}^{-1}$, while the zeolite after acid treatment (CNZ-A) has a vibrational wavenumber asymmetry at $1060.85 \mathrm{~cm}^{-1}$.

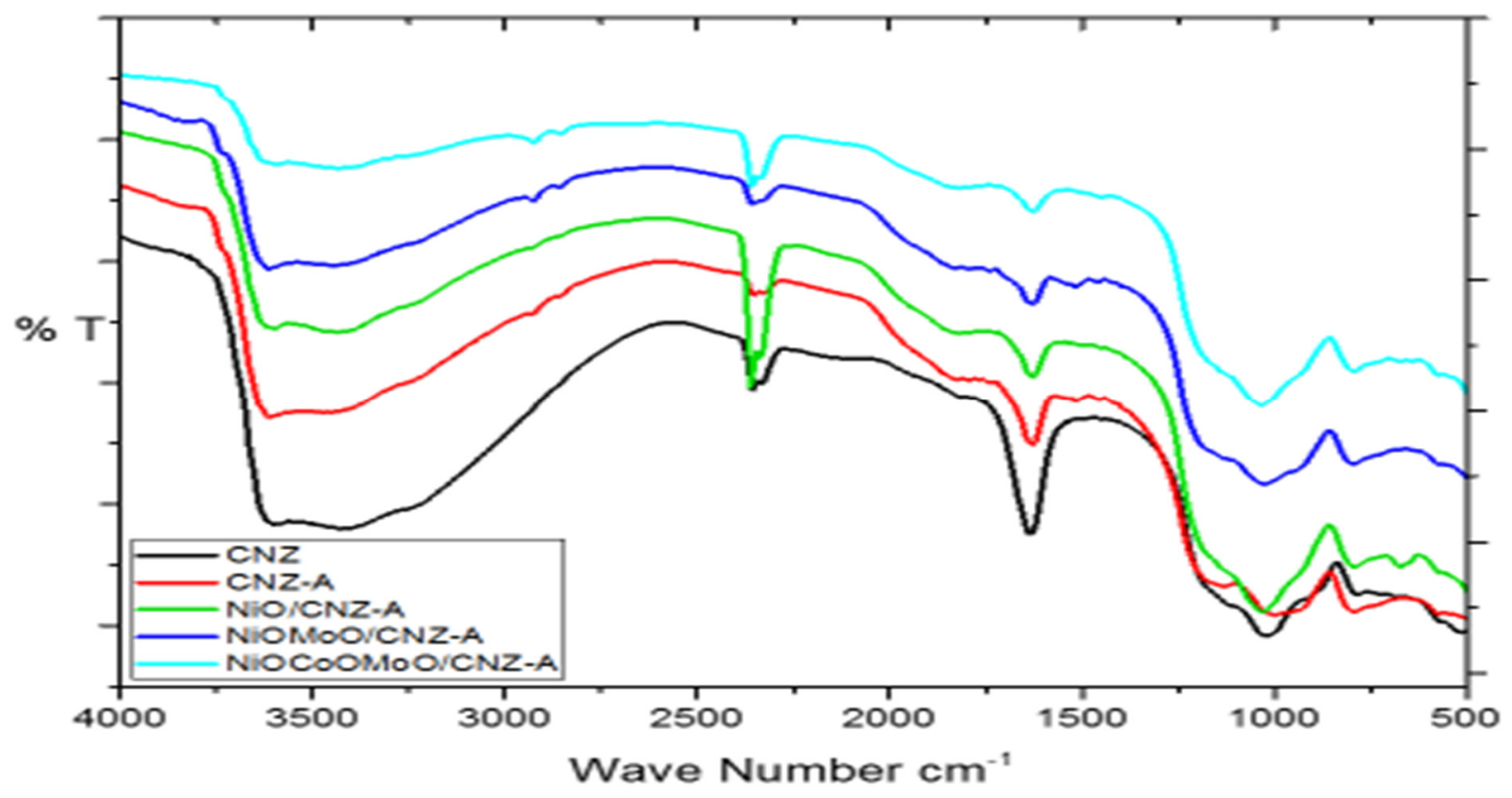

Fig.-1: The Comparison of IR Spectra in all Catalyst

Table-1: The Spectra of Infra-red CNZ Interpretation and its Modifications

\begin{tabular}{|c|c|c|c|c|c|c|}
\hline \multirow{2}{*}{$\begin{array}{c}\text { Standard } \\
\text { Wavenumber }\end{array}$} & \multicolumn{5}{|c|}{ Wavenumber } & \multirow[b]{2}{*}{ Interpretation } \\
\hline & $\mathrm{CNZ}$ & CNZ-A & $\begin{array}{c}\mathrm{NiO} / \\
\mathrm{CNZ}-\mathrm{A}\end{array}$ & $\begin{array}{l}\mathrm{NiOMoO} / \\
\mathrm{CNZ}-\mathrm{A}\end{array}$ & $\begin{array}{l}\mathrm{NiOCoOMoO} / \\
\text { CNZ-A }\end{array}$ & \\
\hline $1250-950$ & 1056 & 1060 & 1033 & 1026 & 1033 & $\begin{array}{c}\text { Asymmetrical Stretching } \\
\text { Vibration O-T-O }\end{array}$ \\
\hline $1650-1645$ & 1635 & 1627 & 1627 & 1627 & 1627 & Bending Vibration Si-OH \\
\hline $3200-3600$ & 3451 & 3610 & 3579 & 3618 & 3433 & Bonding $-\mathrm{OH}$ \\
\hline
\end{tabular}

Table-1 depicts the wavenumber of CNZ and its modification to show a frequency shifted as an effect of asymmetrical stretching vibration for wavenumber of $\mathrm{TO}_{4}$ groups from about $1000-1100 \mathrm{~cm}^{-1}$. The data shows that CNZ had a stretch around $1027 \mathrm{~cm}^{-1}$ and shifted to $1060 \mathrm{~cm}^{-1}$ after the activation process. This shift appeared as an impact of aluminium metal moved from inside framework to the outside framework. The amount of aluminium is equal with a wavenumber of main asymmetric stretching vibration. Then, if there will be a decreasing trend from the amount of aluminium in the zeolite framework, the wavenumber of asymmetric stretching vibration will shift to a larger frequency. However, after the impregnation of $\mathrm{Ni}$, Co and Mo metals in CNZ, the wavenumber of asymmetric stretching vibration was declined. It was possible due to the bending of metals in the framework and strengthens the aluminium bonding in the framework.

X-ray diffraction (XRD) analysis was performed to determine the type of zeolite mineral contained and the crystallinity of the zeolite sample. The type of mineral was shown by the position of diffraction angle (20), while the crystallinity of a sample was shown on their intensity. Figure- 2 shows the XRD pattern of zeolite samples. Most of the peaks were observed at 20 degree of 5-35 for the commercial natural zeolite samples and can be assigned to be those of mordenite type crystalline as reported by Trisunaryanti et al. (1996). ${ }^{17}$ The treatment preparation and activation with acid increased the sample crystallinity which indicated by the intensity of the main peaks, similar to $2 \theta$. 
RASĀYAN J. Chem.

Vol. 12 | No. 1 |205 - 213| January - March | 2019

The acidity of the catalyst was determined by the gravimetric method as shown in Table-2. The acidity of the catalyst was increased as a result of the process of developing the metal into the porous carrier, wherein the acidity of the catalyst has been indicated to be NiO-CoO-MoO/CNZ-A >NiO-MoO/CNZ-A $>\mathrm{NiO} / \mathrm{CNZ}-\mathrm{A}>\mathrm{CNZ}-\mathrm{A}$ respectively. It suggests that the metal acts as Lewis acid sites which have empty $\mathrm{d}$ orbital or half full effective to accept an electron pair from base adsorption. ${ }^{18}$ The inducing metal on zeolite solids dispersed on the surface and inside the pores of the zeolite, which the presence of these metals increase the effectiveness of bases adsorption. It indicates that the metal-induced; $\mathrm{Ni}$, $\mathrm{Co}$ and $\mathrm{Mo}$ in the solid zeolite increase the acidity of the catalyst.
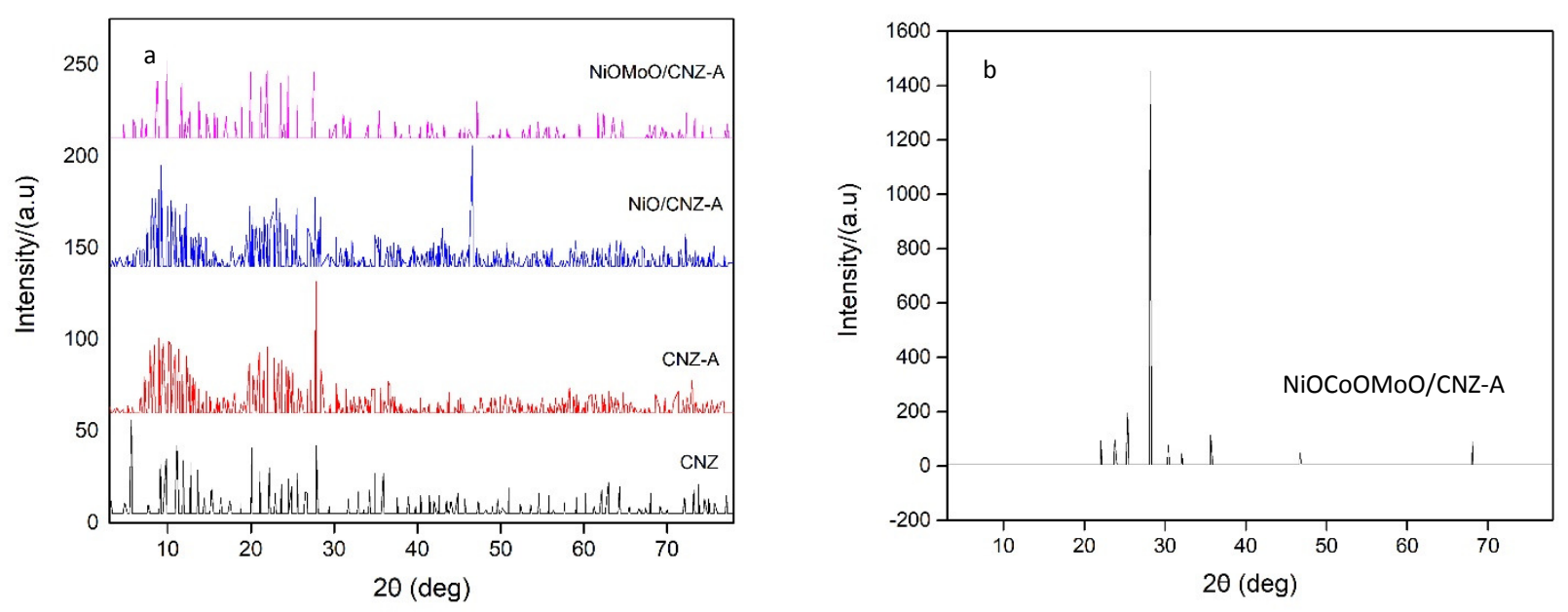

Fig.-2: The XRD Catalyst Patterns of: (a) Cleaned Commercial Natural Zeolite (CNZ), Activated Commercial Natural Zeolite (CNZ-A), NiO/CNZ-AandNiOMoO/CNZ-A and (b) NiOCoOMoO/CNZ-A

Table-2: Specific Surface Area, Mean Pore, Pore Volume Total and Catalyst Acidity

\begin{tabular}{c|c|c|c|c}
\hline Catalyst Name & $\begin{array}{c}\text { Surface Area } \\
\left(\mathrm{m}^{2} / \mathrm{g}\right)\end{array}$ & $\begin{array}{c}\text { Mean Pore } \\
(\AA)\end{array}$ & $\begin{array}{c}\text { Pore Volume } \\
\text { Total }(\mathrm{cc} / \mathrm{g})\end{array}$ & $\begin{array}{c}\text { Ammonia Acidity } \\
(\mathrm{mmol} / \mathrm{g})\end{array}$ \\
\hline $\mathrm{CNZ}$ & 14.845 & 40.153 & $2.980 \times 10^{2}$ & 1.67 \\
\hline $\mathrm{NiO} / \mathrm{CNZ}-\mathrm{A}$ & 12.273 & 62.708 & $3.848 \times 10^{2}$ & 2.67 \\
\hline $\mathrm{NiOMoO/CNZ-A}$ & 9.825 & 51.185 & $2.515 \times 10^{2}$ & 2.07 \\
\hline $\mathrm{NiOCoOMoO/CNZ-A}$ & 10.975 & 46.818 & $2.569 \times 10^{2}$ & 2.23 \\
\hline
\end{tabular}

The addition of metals to CNZ-A induce the changes in the character of the catalyst. Table-2 describes that addition of $\mathrm{Ni}, \mathrm{Co}$ and Mo at $\mathrm{CNZ}$ generally induces a decrease in the specific surface area of the $\mathrm{CNZ}$ catalyst. It is possible due to the uneven dispersion of metal into the pores of the carrier. The uneven pores of metal dispersion are also could be caused by the shape of the carrier surface which is not uniform. It is because of the presence of commercial natural zeolite in addition to mordenite and clinoptilolite also mixed with crystalline or amorphous silica, induce close the active site. Although some efforts to increase the active sites of commercial natural zeolite with acidification and calcination process were determined, they were found to be not optimal yet. Metal dispersion capabilities were influenced by the amount of active surface of solid carrier sites. High numbers of active sites increase the dispersion of metals in the solid bearers. ${ }^{22}$

The NiO/CNZ-A catalyst with metal induce to decrease specific surface area but improve the mean pore and total pore volume. It shows the relationship between the total pore volume and average pore with uneven dispersion of metal induce the closure of the pore cage bearers are small. It gives effect to the pore size distribution shifted towards larger diameter and also induces higher total pore volume. At Catalyst NiO-MoO/CNZ-A, the metal addition of Mo and Ni induce the decrease in specific surface area, mean pore and total pore volume compared to the ZAS and NiO/CNZ-A. In the other hand, at $\mathrm{NiO}-\mathrm{CoO}-\mathrm{MoO} / \mathrm{CNZ}-\mathrm{A}$ catalyst, metal introduces of $\mathrm{Mo}$, Co, and Ni at CNZ-A caused a decrease in 
specific surface areas than CNZ-A and NiO/CNZ-A but increased compared to NiO-MoO/CNZ-A. It is due to the interaction between the metal on the surface of a solid carrier, induce the structuring and formation of new pores on the surface of a solid carrier. This leads to increased surface area and decreased of the mean pore and total pore volume of the catalyst. For all the catalyst variations, the average value of pore catalyst is in the range of $<100 \AA$. It showed that the zeolites which were used as catalysts have a micropores size. ${ }^{18}$

\section{Hydrocracking Process}

MEFA catalytic hydrocracking process used catalyst rice bran of CNZ-A, NiO/CNZ-A, NiO-MoO/CNZ$\mathrm{A}$ and $\mathrm{NiO}-\mathrm{CoO}-\mathrm{MoO} / \mathrm{CNZ}-\mathrm{A}$. This aimed to produce fractions of liquid fuels as gasoline in a higher of amount or percentage than the percentage of diesel fractions. The product consists of liquid products (PC), cokes, residues, and gas. The liquid product obtained is a yellow liquid condensation product of the hydrocracking process. Coke is a solid product in deposits contained in the catalyst after the hydrocracking process. The termination of the carbon chain in the hydrocracking process was through the carboniumion mechanism. ${ }^{23}$ The influence of temperature variations of the liquid product conversion from MEFA rice bran catalytic cracking at CNZ-A catalyst shown in Fig.-3.

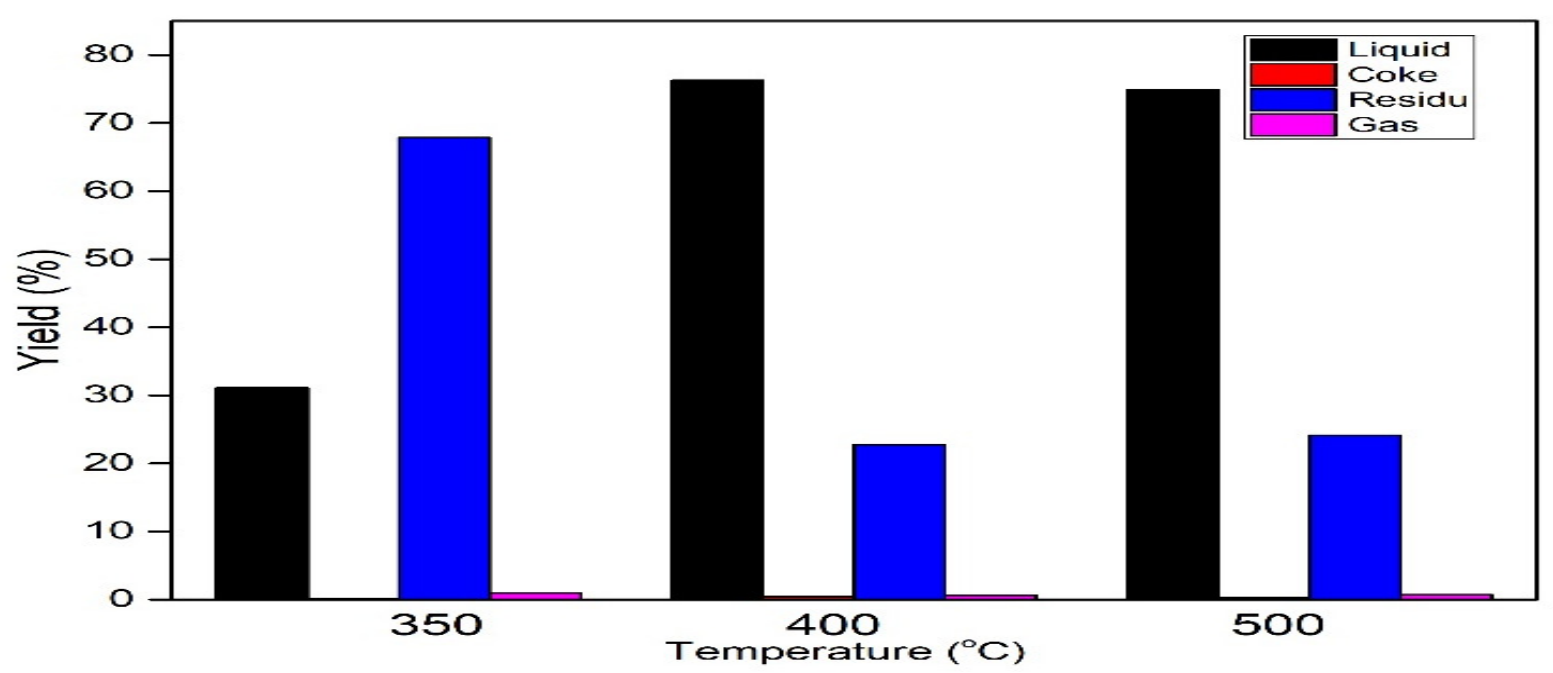

Fig.-3: The Conversion yield of MEFA at various Temperature over CNZ-A catalyst

Figure- 3 shows that the optimum conditions of liquid product produced at $400^{\circ} \mathrm{C}$ process as $76.28 \%$ $(\mathrm{w} / \mathrm{w})$. This reaction temperature was used to determine the effect of catalyst variations in the conversion liquid product. The activity of the catalyst in the hydrocracking process shown on the conversion percent of liquid product produced. ${ }^{23}$ The catalyst used in the hydrocracking process was dual functional a hydrocracking catalyst cracks molecular height-weight hydrocarbons and hydrogenates the unsaturated that are either formed during the cracking step or otherwise present in the feedstock. ${ }^{24}$ The result of the conversion of liquid products for various types of catalysts is presented in Fig.-4.

Figure-4 shows that the MEFA hydrocracking at CNZ-A catalyst provides a lower conversion value of the liquid product as $76.28 \%$ (w/w). Metal introduce of Ni, Ni-Mo, Ni-Co-Mo in the solid zeolite induce an increase in the catalytic activity of the catalyst. The catalyst NiO-CoO-MoO/CNZ-A provides the highest conversion value liquid products as $90.24 \%$ (w/w). It can be influenced by catalyst acidity. The catalyst NiO-CoO-MoO/CNZ-A has higher of a number of acid sites, induced to convert more liquid products compared than other catalysts. The other reason is the $\mathrm{Ni}$, Co and Mo metals that are used as the active sites of hydrocracking in the reaction with unpaired electrons in d orbitals. ${ }^{25}$

MEFA hydrocracking liquid product selectivity of rice bran was analyzed by GC chromatogram and quantitatively. Gasoline and diesel fraction classification were based on the retention time of the compound in the chromatogram. The fraction of gasoline $\left(\mathrm{C}_{5}-\mathrm{C}_{12}\right)$ appears at a retention time before 10 minutes (retention time n-dodecane). 
RASĀYAN J. Chem.

Vol. 12 | No. 1 |205 - 213| January - March | 2019

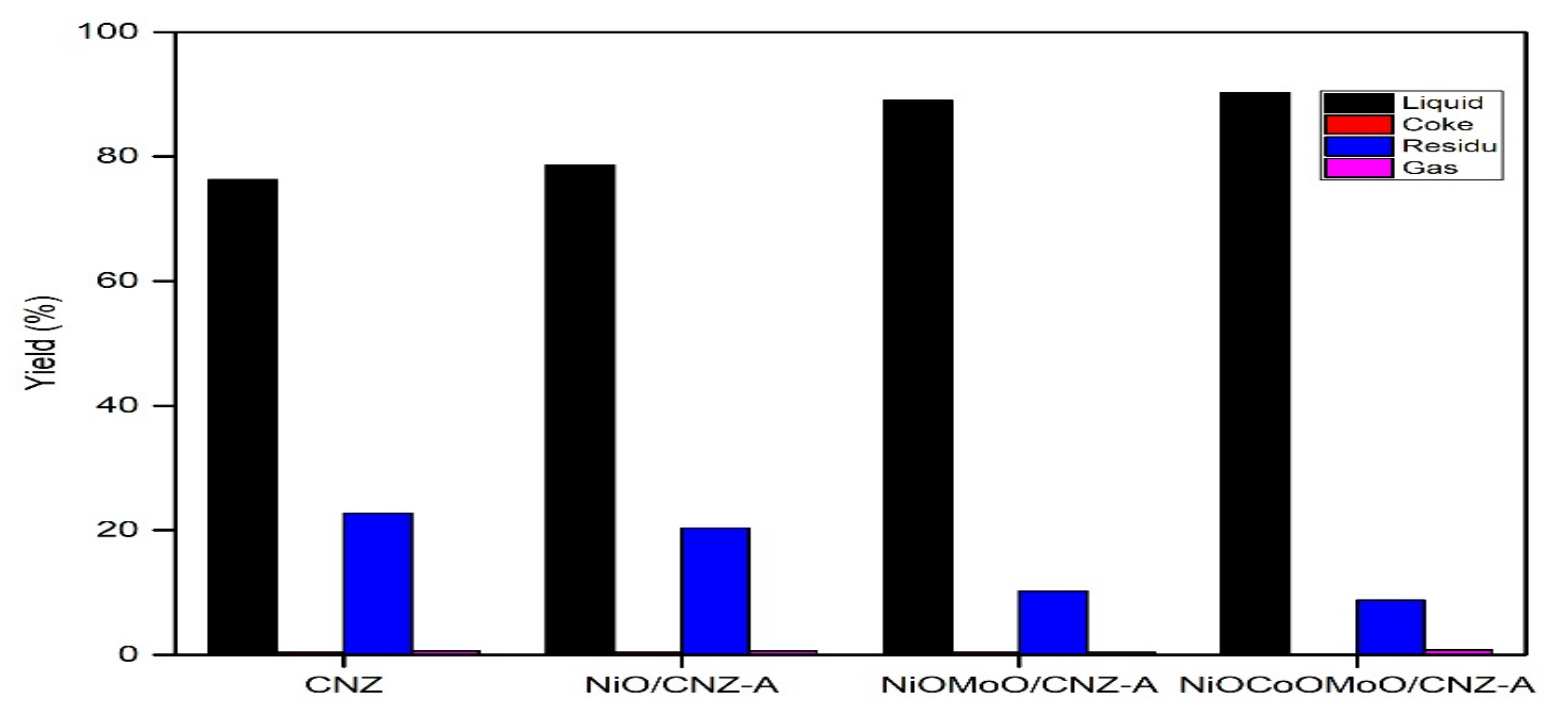

Fig.-4: The Conversion yield of MEFA overall various catalyst at $400^{\circ} \mathrm{C}$

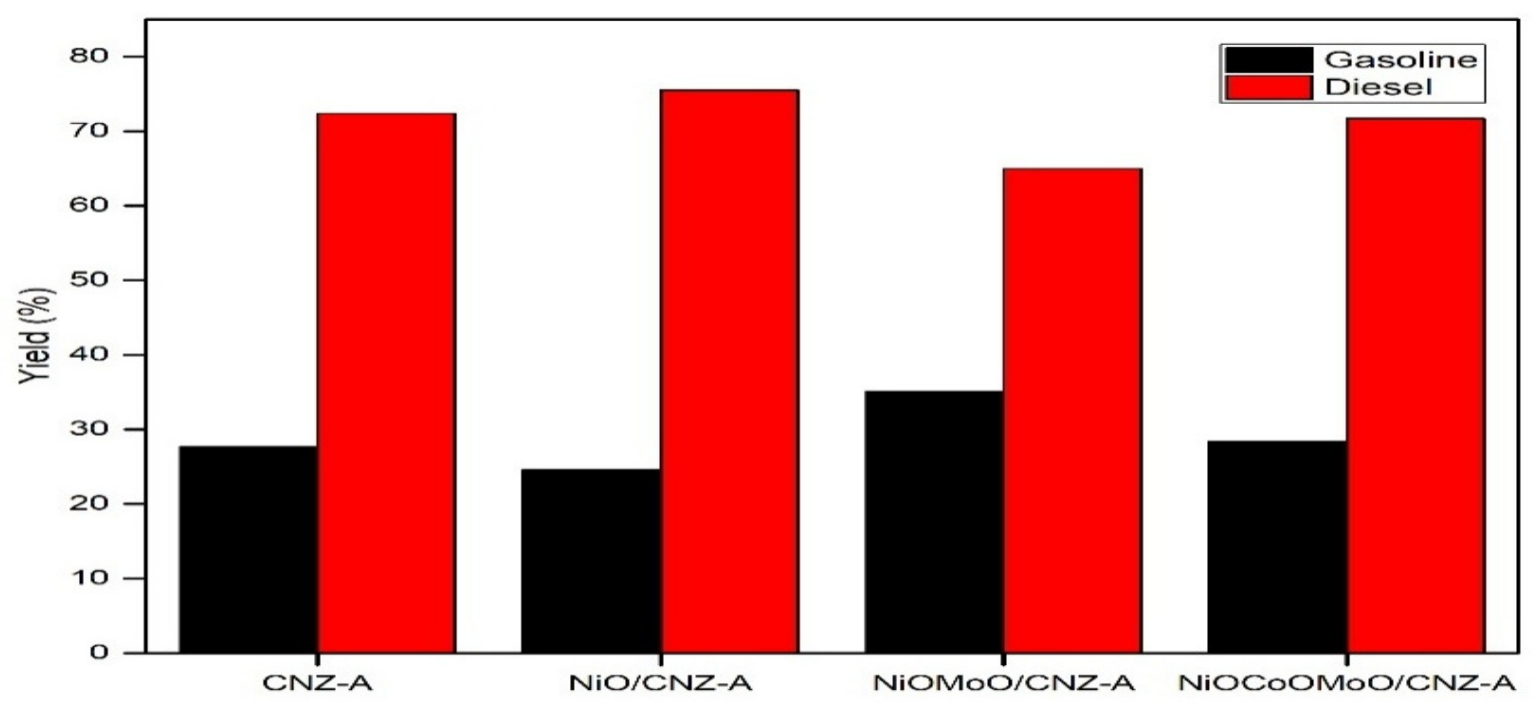

Fig.-5: The Selectivity of liquid yield from hydrocracking process overall various catalyst

The retention time of diesel fraction with the number of carbon atoms $>12$ is over than 10 minutes. ${ }^{18}$ However, the retention time of bio-gasoline and biodiesel can be affected by which raw material is used. ${ }^{26}$ Distribution of gasoline and diesel in liquid products of MEFA hydrocracking rice bran was shown in Figure 5 which the NiO-MoO/CNZ-A catalyst has a relatively higher fraction of the gasoline product selectivity than other catalysts. It indicates the mixed metal catalyst exhibits greater selectivity because the presence of the second metal may have a strong effect on the selectivity of the reaction in which $\mathrm{Ni}$ acts as a promoter and Mo as the catalyst promoter.

Otherwise, NiO-CoO-MoO/CNZ-A catalyst with the highest acidity properties, but has a smaller mean pore of $46.818 \AA$. It suggests that MEFA molecules are more difficult to get into the inner surface of the catalyst. With the high number of acid sites and the smaller size of NiO-CoO-MoO/CNZ-A catalyst, MEFA molecules suggest only to interact on the surface of the catalyst, producing the higher conversion of liquid products, but the lower selectivity to gasoline fraction.

\section{CONCLUSION}

Conversion of rice bran oil into fractions of liquid fuels of gasoline and diesel fractions through esterification and trans-esterification has been carried out with a variety of catalysts. The metal 
introduction to the solid zeolite catalysts has been proven to increase the catalytic activity. The highest liquid products conversion generated by the oxide catalyst of NiO-CoO-MoO/CNZ-A was $90.24 \%(\mathrm{w} / \mathrm{w}$ ), followed by the NiO-MoO/CNZ-A catalyst, NiO/CNZ-A and CNZ of $89.01 \%$ (w/w), $78.63 \%$ (w w) and $76.28 \%(\mathrm{w} / \mathrm{w})$ respectively. Liquid products consist of gasoline and diesel fractions. The highest selectivity of gasoline fraction produced by the NiO/CNZ-A catalyst was $75.46 \%$, followed by CNZ catalyst, $\mathrm{NiO}-\mathrm{CoO}-\mathrm{MoO} / \mathrm{CNZ}-\mathrm{A}$ and $\mathrm{NiO}-\mathrm{MoO} / \mathrm{CNZ}-\mathrm{A}$ with $72.34 \%, 71.65 \%$ and $64,92 \%$ respectively.

\section{ACKNOWLEDGMENT}

The authors would like to thank the Ministry of Research, Technology and Higher Education (Ristekdikti) of Indonesia for the financial support via The Research Program of HIBAH BERSAING 2014 and HIBAH TERAPAN 2017 scheme.

\section{REFERENCES}

1. S. Zeng, M. Kates, M. A. Dube and D. D. McClean, Journal of Biomass and Bioenergy, 30, 267 (2006), DOI: 10.1016/j.biombioe.2005.10.004.

2. N. Jaya and K. Ethirajulu, International Journal of Engineering Science and Technology,3(4),3463 (2011).

3. K. Min Cho, S. Park, J. Gil Seo, M. H. Youn, I. Nam, S. Hyeon Baeck, J. K. Chung, K. W. Jun and I. K. Song, Journal of Chemical Engineering, 146, 307 (2009), DOI: 10.1016/j.cej.2008.10.008.

4. S. Charusiri and T. Vitidsant, Energie and Fuels, 19(5), 1783 (2005), DOI: 10.1021/ef0500181.

5. J. C. A. Gaya,Biodiesel from Rape Seed Oil and Used Frying Oil in European Union, Copernicus Institute, Universiteit Utrecht (2003).

6. N. Sirajudin, K. Jusoff, S. Yani, L. Ifa, and A. Roesyadi, World Applied Science Journal, 26, 676 (2012).

7. L. Mahardiani, E. Kurniawan, W. Trisunaryanti and Triyono, Jurnal Molekul, 6(2), 105 (2011).

8. M. Nasikin, H. B. Susanto, M. A. Hirsaman and A. Wijarnoko, World Applied Science Journal, 5, 74 (2009).

9. O. Y. Sang,Energy Sources, 25(9), 859 (2003), DOI: 10.1080/00908310390221309.

10. F. Twaiq, A. R. Mohammed and S. Bhatia, Microporous and Mesoporous Materials, 64(1-3), 95 (2003), DOI: 10.1016/j.micromeso.2003.06.001.

11. A. Demirbas, Energy Sources,25(5), 457 (2003), DOI: 10.1080/00908310390142451.

12. H. Fukuda, A. Kondo and H. Moda, Journal of Bioscience and Bioengineering, 92(5), 405 (2001), DOI: $10.1016 / \mathrm{S} 1389-1723(01) 80288-7$.

13. K. Tyson,Biodiesel Handling and Use Guideline, National Renewable Energy Laboratory, Mild West (2009).

14. A. A. Wibowo, S. Firdausyah, S. Hajjah, D. Dwiyanti, J. L. Sihombing and A. N. Pulungan, In Proceedings of The First International Seminar on Trends in Science and Science Education, Medan, Indonesia, pp. 132-140 (2014).

15. U. Ghosh, K. Kulkarni, A. D. Kulkarni and P. L. Chaudhari, Chemical and Process Engineering Research, 34, 51 (2015).

16. W. Trisunaryanti, T. Endang and S. Sri, Indonesian Journal of Chemistry, 5(1), 48 (2005).

17. W. Trisunaryanti, R. Shiba, M. Miura, M. Namura, N. Nashiyama and M. Matsukata, Journal of the Japan Petroleum, 39(1), 20 (1996), DOI: 10.1627/jpi1958.39.20.

18. W. Trisunaryanti, Triyono, K. Wijaya, A. B. Madjid, Y. Priastomo, E. Febriyanti, Syafitri, Hasyyati, and A. Nugroho, In proceedings of Seminar Nasional Kimia Unesa, Surabaya, Indonesia, pp. 102113 (2012).

19. S. Indrayanah, A. Rosyidah, H. Setyawati and I. K. Murwani, Rasayan Journal Chemistry, 11(1), 312(2018), DOI: 10.7324/RJC.2018.1111904

20. W. Trisunaryanti, A. Syoufian and S. Purwono, Journal of Chemistry and Chemical Engineering, 7, 175 (2013).

21. P. Saraswathi and M. Makeswari, Rasayan Journal Chemistry, 10(3), 759(2017), DOI: 10.7324/RJC.2017.1031752

22. A. N. Pulungan, J. L. Sihombing, H. I. Nasution, R. E. Dibyantini, R. Selly, W. Trisunaryanti and 
RASĀYAN J. Chem.

Vol. 12 | No. 1 |205 - 213| January - March | 2019

Triyono, In Proceedings of The First International Seminar on Trend in Science and Science Education, Medan, Indonesia, pp. 148- 154 (2013).

23. H. Kusumawati, W. Trisunaryati, I. I. Falah and M. F. Marsuki, Rasayan Journal of Chemistry, 11(2), 552(2018), DOI: 10.7324/RJC.2018.1122061

24. M. A. Ali, T. Tatsumi and T. Masuda, Applied Catalysis A: General, 233, 77 (2002), DOI: 10.1016/S0926-860X(02)00121-7.

25. H. Kusumawati, W. Trisunaryati, I. I. Falah and M. F. Marsuki, Rasayan Journal of Chem., 11(2), 552(2018), DOI: 10.7324/RJC.2018.1122061

26. J. L. Sihombing, S. Gea, A. Kembaren, Sabani, A. N. Pulungan, A. A. Wibowo, and B. Wirjosentono, Journal of Physics: Conference Series, 1116, 042035(2018), DOI: 10.1088/1742$6596 / 1116 / 4 / 042035$

[RJC-5036/2018] 